\title{
ALTERNATIF POLA OPERASI EMBUNG SUKODONO KECAMATAN PANCENG KABUPATEN GRESIK UNTUK KEBUTUHAN AIR BAKU DAN AIR IRIGASI
}

\section{ALTERNATIVE OPERATION PATTERNS OF SUKODONO DAM IN PANCENG SUB- DISTRICT GRESIK DISTRICT FOR THE NEEDS OF RAW WATER AND IRRIGATION WATER}

\author{
Ernawan Setyono ${ }^{1}$, Amirul Satrio Rudianto ${ }^{2}$ \\ 1,2 Jurusan Teknik Sipil-Fakultas Teknik-Universitas Muhammadiyah Malang \\ Kampus III Jl. Tlogomas No.246 Tlp. (0341) 464318 \\ Email: ernawan@umm.ac.id; amirulsatrio@gmail.com
}

\begin{abstract}
Water is a basic necessity that is very important to fulfill human needs and increases along with the human population, while water supply on earth remains. An effort to overcome this problem is by storing water in the reservoir. Embung Sukodono has a maximum storage capacity of 1,547 million $\mathrm{m}^{3}$. Embung Sukodono utilizes the downstream Bengawan Solo river supply located in Sekargadung village with a planned pumping inflow of 230 liters / second to supply the outflow in form of raw water and irrigation needs of the community of Panceng and Dukun Subdistricts until 2039. Raw water requirements at peak hours at in 2039 it was 73.76 liters / second and the maximum irrigation requirement was 250.93 liters / second covering an area of 250 hectares. In this study the simulation of dam operation pattern plan was divided into 3 pumping alternatives. From the simulation result of Embung Sukodono's operating plan, the operational pattern plan used for 25 years was alternative 3. In alternative 3 the pumping discharge capacity could be reduced from 230 liters / second to 200 liters / second during the dry season and pumping time could be reduced from 12 hours pumping became 8 hours pumping in the dry season but the water level was maintained above the minimum operating elevation.
\end{abstract}

Keywords: Inflow; Outflow; Operation Pattern; Dam

\begin{abstract}
Abstrak
Air merupakan kebutuhan pokok yang sangat penting untuk memenuhi kelangsungan hidup manusia dan semakin meningkat seiring dengan meningkatnya jumlah penduduk, sedangkan persediaan air di bumi tetap. Salah satu upaya mengatasi masalah tersebut adalah dengan menampung air di embung. Embung Sukodono mempunyai kapasitas tampungan maksimum sebesar 1,547 juta $\mathrm{m}^{3}$.Embung Sukodono memanfaatkan suplesi sungai Bengawan Solo bagian hilir yang terletak di desa Sekargadung dengan inflow debit pemompaan rencana sebesar 230 liter/detik untuk memenuhi outflow berupa kebutuhan air baku dan irigasi masyarakat Kecamatan Panceng dan Kecamatan Dukun hingga tahun 2039. Kebutuhan air baku pada jam puncak pada tahun 2039 sebesar 73,76 liter/detik dan kebutuhan irigasi maksimum sebesar 250,93 liter/detik seluas $250 \mathrm{Ha}$. Dalam studi ini simulasi pola operasi embung terbagi menjadi 3 alternatif pemompaan. Dari hasil simulasi rencana pola operasi Embung Sukodono, rencana pola operasi yang digunakan selama 25 tahun adalah alternatif 3. Pada alternatif 3 kapasitas debit pemompaan dapat diturunkan dari 230 lt/dtk menjadi 200 lt/dtk pada musim kering dan lama pemompaan dapat diturunkan dari 12 jam pemompaan menjadi 8 jam pemompaan pada musim kering namun elevasi muka air embung tetep terjaga di atas elevasi tampungan minimum operasi.
\end{abstract}

Kata Kunci : Inflow; Outflow; Pola Operasi; Embung 


\section{PENDAHULUAN}

Air adalah salah satu kebutuhan pokok dalam kehidupan manusia. Fungsi air bagi manusia diantaranya untuk air baku, air irigasi, pembangkit listrik dan sebagainya. Seiring dengan pertumbuhan manusia yang semakin meningkat maka kebutuhan air semakin banyak, namun ketersediaan air di bumi tidak mengalami peningkatan. Untuk itu diperlukan pendistribusian air agar dapat memenuhi kebutuhan manusia. Agar pendistribusian dapat optimal saat musim kemarau dan musim penghujan, maka diperlukan pembangunan embung.

Embung Sukodono merupakan embung gali dengan luas DAS sebesar embung itu sendiri $\left(0,36 \mathrm{~km}^{2}\right)$. Embung dibangun dengan memanfaatkan suplesi Sungai Bengawan Solo bagian hilir yang terletak di Desa Sekargadung, Kecamatan Dukun, Kabupaten Gresik. Sesuai topografi, Embung Sukodono memiliki elevasi lebih tinggi dibandingkan elevasi muka air Sungai Bengawan Solo hilir sehingga di butuhkan pompa untuk mengisi embung. Embung Sukodono memiliki fungsi untuk menampung kelebihan air pada Sungai Bengawan Solo saat musim hujan tiba, pada saat musim kemarau digunakan untuk kebutuhan air baku dan air irigasi seluas 250 Ha. Ada beberapa bangunan pada Embung Sukodono antara lain yaitu tubuh embung, Pipa Baja, dan rumah pompa. Tubuh embung mempunyai tinggi $7,00 \mathrm{~m}$ dan lebar puncak $3,00 \mathrm{~m}$. Pipa baja yang digunakan untuk membawa aliran air dari sungai bengawan solo sepanjang 7,4 $\mathrm{Km}$ namun dikarenakan adanya perubuhan jalur maka perencanaan panjang pipa menjadi $8,2 \mathrm{Km}$. Pada bagian Rumah pompa, pompa di letakan pada elevasi $+6,00$ dengan rencana pengambilan sebesar $230 \mathrm{lt} / \mathrm{dt}$.

Dalam analisa tampungan, embung akan dibedakan menjadi tampungan minumum dan tampungan maksimum. Tampungan minimum adalah tampungan yang digunakan untuk menampung air pada elevasi terendah selama umur ekonomis yang direncanakan. Sesuai dengan kajian perencana, diperoleh tampungan minimum sebesar 111.972,54 $\mathrm{m}^{3}$. Sedangkan tampungan maksimum adalah tampungan yang digunakan untuk menampung air pada elevasi tertinggi untuk keperluan embung.
Tampungan maksimum embung sebesar $1.547 .014,36 \mathrm{~m}^{3}$. (PT. WECON)

Dalam memanfaatkan tampungan embung, pemakaian air harus dilakukan sebaik mungkin. Untuk itu diperlukan rencana pola operasi Embung Sukodono agar dapat memenuhi berbagai kebutuhan sesuai dengan yang direncanakan

\section{METODE PENELITIAN}

\section{Pengumpulan Data}

Pengumpulan data pada dasarnya adalah suatu kegiatan dimana harus mendapatkan data yang di butuhkan dalam menunjang laporan. Data sendiri merupakan informasi yang sengaja di gali atau di kumpulkan guna mendeskripsikan permasalahan yang di angkat. Proses pengumpulan data ini untuk menghindari data yang tidak benar yang nantinya akan berpengaruh pada laporan yang akan dibuat. Ada pula data yang digunakan dalam pengerjaan skripsi ini diantara ialah

1. Data Penduduk

2. Data Pola Tanam

3. Data Klimatologi

4. Data Hidrologi

5. Data Teknis dan Pemompaan

\section{Langkah - Langkah Pengerjaan}

Untuk memperlancar langkah-langkah perhitungan dalam studi ini maka diperlukan tahapan-tahapan sebagai berikut :

1. Perhitungan kebutuhan air baku sesuai proyeksi penduduk tahun 2039

2. Pengolahan data klimatologi

Data klimatologi diperlukan untuk menghitung nilai evaporasi dan evapotranspirasi.

3. Pengolahan data hujan

Data Hujan diperlukan untuk menghitung curah hujan efektif

4. Perhitungan kebutuhan irigasi.

5. Perumusan model simulasi tampungan dengan menggunakan Microsoft Excel. dengan langkah-langkah sabagai berikut :

- Menentukan bulan dan periode serta jumlah hari.

- Menentukan tampungan awal bulan atau tampungan awal operasi, dalam studi ini tampungan awal yang diambil pada elevasi maksimum operasi.

- Elevasi awal bulan diambil saat muka air pada elevasi tertinggi. Elevasi air 
yang didasarkan dari luas tampungan total.

- Luas genangan embung diambil dari data karakteristik embung berdasarkan tampungan total embung. Luas genangan diperlukan untuk memperoleh nilai kehilangan air di embung akibat evaporasi.

- Menentukan kehilangan air di embung akibat evaporasi. Kehilangan air di embung sangat dipengaruhi oleh luas tampungan. Makin luas tampungan makin besar penguapan yang terjadi.

- Menentukan debit keluaran (ouflow) dari embung. Diperoleh dari besarnya rata - rata kebutuhan air baku pada jam puncak dan irigasi.

- Menghitung besarnya tampungan akhir. Tampungan akhir merupakan nilai dari tampungan awal ditambahkan dengan selisih antara debit inflow dan debit outflow. Pada awal perhitungan debit inflow ditambahkan dengan tampungan maksimum operasi, sedangkan debit outflow ditambah dengan nilai evaporasi. Untuk bulan selanjutnya nilai tampungan akhir bulan sebelumnya digunakan sebagai tampungan awal pada bulan itu.

- Proses tersebut berulang hingga tampungan akhir periode ini (1 tahun).

Diagram Alir penelitian tersaji pada gambar 1.

\section{HASIL DAN PEMBAHASAN}

\section{Analisa Klimatologi}

Data klimatologi dibutuhkan guna mengetahui nilai evapotranspirasi. Data-data yang diperoleh dari stasiun klimatologi adalah temperatur rata-rata $(\mathrm{t})$, kelembapan relatif $(\mathrm{Rh})$, lama penyinaran matahari $(\mathrm{n} / \mathrm{N})$, dan kecepatan angin (U). Data klimatologi yang digunakan adalah tahun 2016-2017 dengan periode 15 harian.

\section{Menghitung Evapotranspirasi}

Evapotranspirasi merupakan gabungan dari proses penguapan air bebas (evaporasi) dan penguapan melalui tanaman (transpirasi). Untuk menghitung evapotranspirasi dalam menggunakan rumus standar FAO. Adapun hasil evapotranspirasi 15 harian tersaji pada Gambar 2.

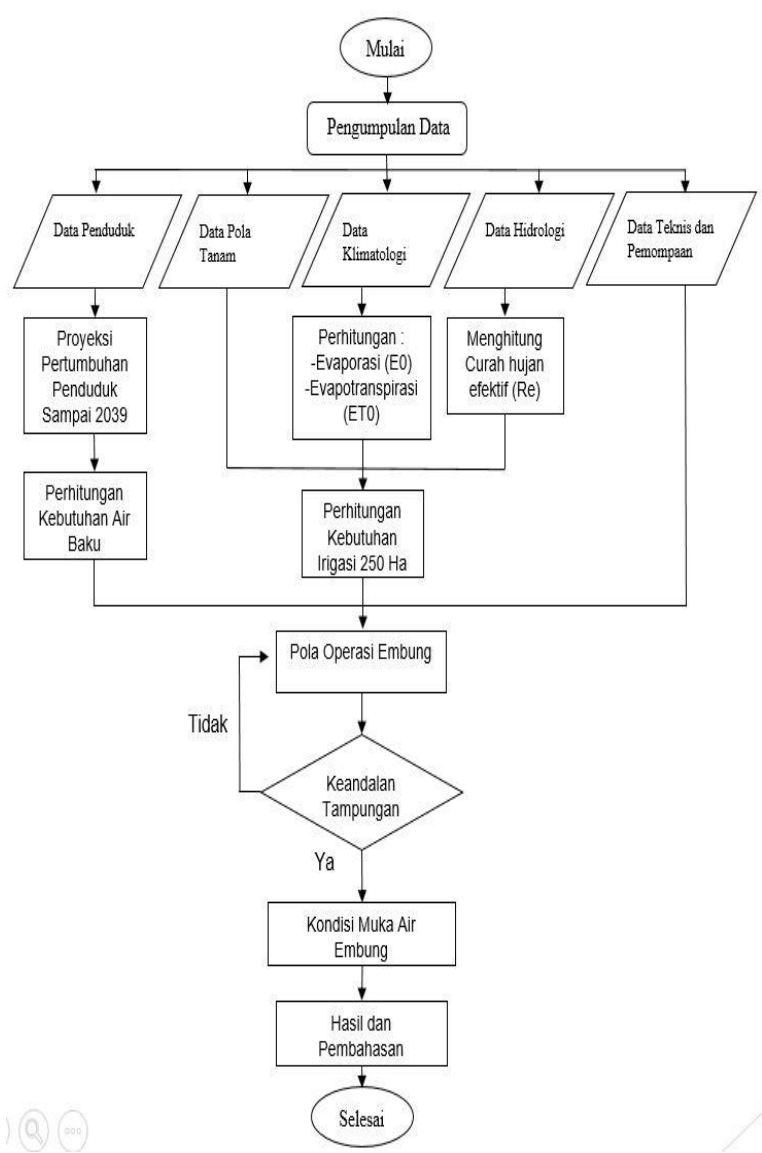

Gambar 1. Diagram Alir Penelitian

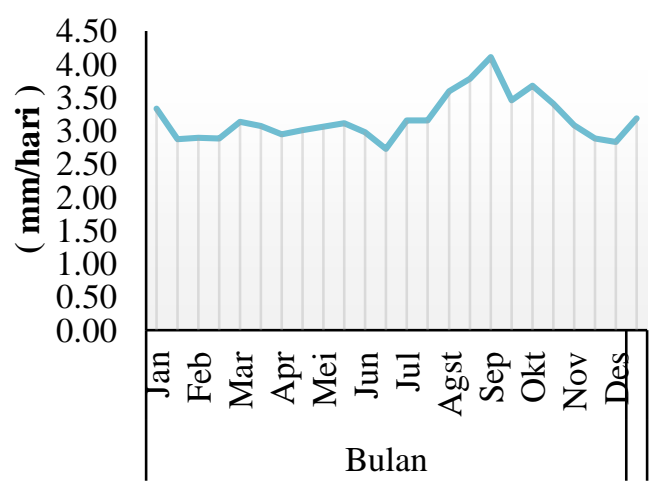

Gambar 2. Grafik rerata evapotranspirasi 15 harian

\section{Menghitung Evaporasi}

Evaporasi adalah proses perubahan molekul dalam cair (air) dengan spontan menjadi gas. Faktor-faktor yang mempengaruhi evaporasi adalah suhu (t), kecepatan angin $(\mathrm{u})$, kelembapan relatif $(\mathrm{Rh})$, dan lama penyinaran matahari (\%). Adapun hasil evaporasi 15 harian tersaji pada Gambar 3. 


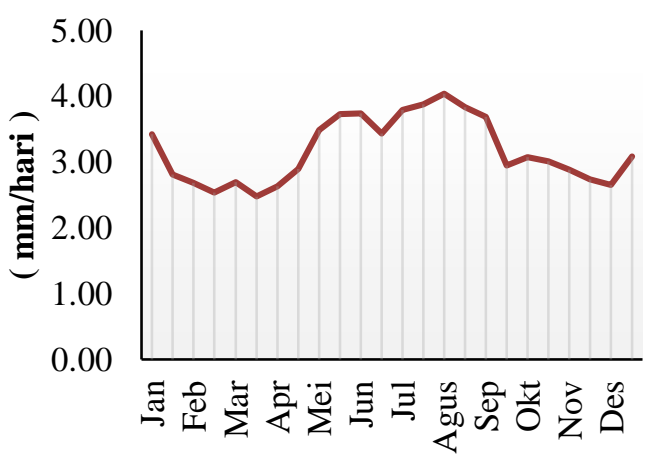

Gambar 3. Grafik rerata evaporasi 15 harian

\section{Menghitung Curah Hujan Andalan}

Analisa hidrologi ini digunakan untuk menghitung curah hujan andalan dengan cara mengubah data hujan 10 tahun menjadi data hujan 15 harian. Setelah diubah menjadi data 15 harian lalu dirangking dari yang terbesar ke terkecil dan menghitung probabilitas menggunakan persamaan Weibull. Tabel 1 menjelaskan mengenai curah hujan andalan basic month.

Tabel 1. Curah Hujan Andalan Basic Month

\begin{tabular}{|c|c|c|c|c|c|c|c|c|c|c|c|}
\hline \multirow{2}{*}{$\frac{\mathrm{N}_{0}}{\mathrm{P}(\%)}$} & & \multirow{2}{*}{$\begin{array}{c}1 \\
9.09 \\
\end{array}$} & \multirow{2}{*}{\multicolumn{2}{|c|}{$\begin{array}{cr}2 \quad 3 \\
18.1827 .\end{array}$}} & \multirow{2}{*}{$\frac{4}{36.36}$} & \multirow[b]{2}{*}{45.45} & \multirow[b]{2}{*}{54.55} & \multirow[b]{2}{*}{03.64} & \multirow[b]{2}{*}{72.73} & \multirow{2}{*}{\multicolumn{2}{|c|}{$\begin{array}{rr}9 & 10 \\
\end{array}$}} \\
\hline & & & & & & & & & & & 90.91 \\
\hline \multirow{2}{*}{ Jan } & I & 210 & 191 & 173 & 172 & 153 & 129 & 111 & 55 & 23 & 0 \\
\hline & II & 216 & 191 & 171 & 140 & 139 & 118 & 97 & 82 & 36 & 0 \\
\hline \multirow{2}{*}{ Feb } & I & 317 & 204 & 183 & 167 & 149 & 147 & 103 & 83 & 6 & 0 \\
\hline & II & 184 & 170 & 143 & 116 & 116 & 103 & 103 & 91 & 73 & 0 \\
\hline \multirow{2}{*}{ Mar } & I & 225 & 167 & 164 & 120 & 118 & 113 & 113 & 103 & 95 & 71 \\
\hline & II & 284 & 188 & 155 & 155 & 153 & 140 & 132 & 121 & 101 & 41 \\
\hline \multirow{2}{*}{ Apr } & I & 180 & 167 & 157 & 142 & 111 & 106 & 97 & 72 & 69 & 17 \\
\hline & II & 119 & 114 & 97 & 94 & 90 & 48 & 40 & 35 & 24 & 2 \\
\hline \multirow{2}{*}{ Mei } & I & 161 & 141 & 115 & 104 & 96 & 82 & 41 & 35 & 34 & 27 \\
\hline & II & 211 & 126 & 74 & 53 & 52 & 46 & 15 & 10 & 9 & 0 \\
\hline \multirow{2}{*}{ Jun } & I & 97 & 63 & 43 & 37 & 34 & 23 & 3 & 0 & 0 & 0 \\
\hline & II & 72 & 53 & 21 & 14 & 10 & 5 & 3 & 0 & 0 & 0 \\
\hline \multirow{2}{*}{ Jul } & I & 122 & 81 & 70 & 23 & 23 & 22 & 16 & 0 & 0 & 0 \\
\hline & II & 51 & 48 & 39 & 23 & 2 & 1 & 0 & 0 & 0 & 0 \\
\hline \multirow{3}{*}{ Ags } & I & 10 & 9 & 4 & 0 & 0 & 0 & 0 & 0 & 0 & 0 \\
\hline & II & 41 & 6 & 1 & 0 & 0 & 0 & 0 & 0 & 0 & 0 \\
\hline & I & 138 & 0 & 0 & 0 & 0 & 0 & 0 & 0 & 0 & 0 \\
\hline Sep & II & 114 & 36 & 3 & 3 & 1 & 0 & 0 & 0 & 0 & 0 \\
\hline \multirow{2}{*}{$0 \mathrm{kt}$} & I & 143 & 104 & 51 & 15 & 0 & 0 & 0 & 0 & 0 & 0 \\
\hline & II & 142 & 98 & 55 & 20 & 8 & 1 & 0 & 0 & 0 & 0 \\
\hline \multirow{2}{*}{ Nov } & I & 154 & 138 & 117 & 114 & 113 & 51 & 31 & 12 & 9 & 0 \\
\hline & II & 299 & 220 & 181 & 161 & 138 & 136 & 104 & 76 & 41 & 41 \\
\hline \multirow{2}{*}{ Des } & I & 232 & 216 & 213 & 183 & 180 & 139 & 111 & 88 & 77 & 55 \\
\hline & II & 413 & 285 & 175 & 174 & 166 & 121 & 108 & 96 & 87 & 84 \\
\hline
\end{tabular}

\section{Menghitung Curah Hujan Efektif}

Curah hujan efektif merupakan curah hujan yang jatuh pada suatu daerah dan dapat digunakan tanaman untuk pertumbuhannya untuk memenuhi kebutuhan air akibat evapotranspirasi tanaman. Perhitungan Curah hujan efektif berdasarkan kebutuhan irigasi untuk tanaman Jagung seluas 250 Ha tersaji pada Tabel 2.

\section{Tabel 2. Curah Hujan Efektif}

\begin{tabular}{|c|c|c|c|}
\hline Bulan & Periode & R80 & $\begin{array}{c}\text { Re Palawija } \\
(\mathrm{mm} / \mathrm{hari}) \\
(\mathrm{R} 80 \times 0,5) / 15\end{array}$ \\
\hline \multirow{2}{*}{ Januari } & I & 23 & 0.77 \\
\hline & II & 36 & 1.2 \\
\hline \multirow{2}{*}{ Februari } & I & 6 & 0.2 \\
\hline & II & 73 & 2.43 \\
\hline \multirow{2}{*}{ Maret } & I & 95 & 3.17 \\
\hline & II & 101 & 3.37 \\
\hline \multirow{2}{*}{ April } & I & 69 & 2.3 \\
\hline & II & 24 & 0.8 \\
\hline \multirow{2}{*}{ Mei } & I & 34 & 1.13 \\
\hline & II & 9 & 0.3 \\
\hline \multirow{2}{*}{ Juni } & I & O & O \\
\hline & II & O & O \\
\hline \multirow{2}{*}{ Juli } & I & o & O \\
\hline & II & O & O \\
\hline \multirow{2}{*}{ Agustus } & I & O & O \\
\hline & II & o & O \\
\hline \multirow{2}{*}{ September } & I & o & o \\
\hline & II & o & O \\
\hline \multirow{2}{*}{ Oktober } & I & $\mathrm{O}$ & o \\
\hline & II & $\mathrm{O}$ & O \\
\hline \multirow{2}{*}{ November } & I & 9 & 0.3 \\
\hline & II & 41 & 1.37 \\
\hline \multirow{2}{*}{ Desember } & I & 77 & 2.57 \\
\hline & II & 87 & 2.9 \\
\hline
\end{tabular}

\section{Menghitung Kebutuhan Irigasi}

Setelah menghitung Evapotranspirasi dan curah hujan efektif maka kebutuhan irigasi sesuai pola tata tanam dapat dihitung dengan hasil pada Tabel 3.

\section{Menghitung Proyeksi Penduduk}

Untuk mengetahui besar kebutuhan air baku di kecamatan Panceng dan Dukun, diperlukan perhitngan jumlah proyeksi penduduk 25 tahun kedepan mulai dari tahun 2014 sampai tahun 2039. Tabel 4 berisi proyeksi jumlah penduduk di kecamatan Panceng dan Dukun menggunakan metode geometrik. 
Tabel 3. Kebutuhan Irigasi

\begin{tabular}{|c|c|c|c|c|c|}
\hline \multirow{3}{*}{ Bulan } & \multirow{3}{*}{ Periode } & \multicolumn{4}{|c|}{ Jagung - Jagung - Jagung } \\
\hline & & \multirow{2}{*}{$\frac{\text { DR }}{1 \mathrm{t} / \mathrm{dt} / \mathrm{ha}}$} & \multirow{2}{*}{$\begin{array}{c}\text { Luas Daerah } \\
\mathrm{Ha}\end{array}$} & \multicolumn{2}{|c|}{ Q Perlu } \\
\hline & & & & $1 \mathrm{t} / \mathrm{dt}$ & $\mathrm{m} 3 / \mathrm{dt}$ \\
\hline \multirow{2}{*}{ Nov } & 1 & 0.86 & 250 & 214.54 & 0.21 \\
\hline & 2 & 0.54 & 250 & 134.18 & 0.13 \\
\hline \multirow{2}{*}{ Des } & 1 & 0.24 & 250 & 60.51 & 0.06 \\
\hline & 2 & 0.23 & 250 & 57.15 & 0.06 \\
\hline \multirow{2}{*}{ Jan } & 1 & 0.74 & 250 & 184.23 & 0.18 \\
\hline & 2 & 0.66 & 250 & 165.20 & 0.17 \\
\hline \multirow{2}{*}{ Feb } & 1 & 0.84 & 250 & 210.39 & 0.21 \\
\hline & 2 & 0.35 & 250 & 86.64 & 0.09 \\
\hline \multirow{2}{*}{ Mar } & 1 & 0.17 & 250 & 43.08 & 0.04 \\
\hline & 2 & 0.13 & 250 & 32.83 & 0.03 \\
\hline \multirow{2}{*}{ Apr } & 1 & 0.40 & 250 & 100.53 & 0.10 \\
\hline & 2 & 0.76 & 250 & 189.49 & 0.19 \\
\hline \multirow{2}{*}{ Mei } & 1 & 0.71 & 250 & 176.27 & 0.18 \\
\hline & 2 & 0.76 & 250 & 190.40 & 0.19 \\
\hline \multirow{2}{*}{ Jun } & 1 & 0.72 & 250 & 179.86 & 0.18 \\
\hline & 2 & 0.69 & 250 & 172.52 & 0.17 \\
\hline \multirow{2}{*}{ Jul } & 1 & 0.85 & 250 & 211.27 & 0.21 \\
\hline & 2 & 0.93 & 250 & 231.65 & 0.23 \\
\hline \multirow{2}{*}{ Ags } & 1 & 1.00 & 250 & 250.93 & 0.25 \\
\hline & 2 & 0.91 & 250 & 228.53 & 0.23 \\
\hline \multirow{2}{*}{ Sept } & 1 & 0.86 & 250 & 214.03 & 0.21 \\
\hline & 2 & 0.78 & 250 & 194.71 & 0.19 \\
\hline \multirow{2}{*}{ Okt } & 1 & 0.93 & 250 & 231.73 & 0.23 \\
\hline & 2 & 0.97 & 250 & 242.76 & 0.24 \\
\hline
\end{tabular}

Tabel 4. Proyeksi Penduduk

\begin{tabular}{|c|c|c|}
\hline No & Tahun & Proyeksi Penduduk \\
\hline 0 & 2014 & 24438 \\
\hline 1 & 2015 & 24651 \\
\hline 2 & 2016 & 24865 \\
\hline 3 & 2017 & 25081 \\
\hline 4 & 2018 & 25300 \\
\hline 5 & 2019 & 25520 \\
\hline 6 & 2020 & 25742 \\
\hline 7 & 2021 & 25966 \\
\hline 8 & 2022 & 26192 \\
\hline 9 & 2023 & 26419 \\
\hline 10 & 2024 & 26649 \\
\hline 11 & 2025 & 26881 \\
\hline 12 & 2026 & 27115 \\
\hline 13 & 2027 & 27351 \\
\hline 14 & 2028 & 27589 \\
\hline 15 & 2029 & 27829 \\
\hline 16 & 2030 & 28071 \\
\hline 17 & 2031 & 28315 \\
\hline 18 & 2032 & 28562 \\
\hline 19 & 2033 & 28810 \\
\hline 20 & 2034 & 29061 \\
\hline 21 & 2035 & 29314 \\
\hline 22 & 2036 & 29569 \\
\hline 23 & 2037 & 29826 \\
\hline 24 & 2038 & 30085 \\
\hline 25 & 2039 & 30347 \\
\hline
\end{tabular}

\section{Menghitung Proyeksi Kebutuhan Air Baku}

Tingkat kebutuhan air untuk keperluan domestik antara satu wilayah dengan wilayah lain akan sangat berbeda. Dalam studi ini perhitungan kebutuhan air baku penduduk berdasarkan pada pedoman PU tersaji pada tabel 5.

Tabel 5. Rekapitulasi Kebutuhan Air Baku

\begin{tabular}{|c|c|}
\hline \multirow{2}{*}{ Uraian } & Tahun \\
\hline & $\begin{array}{llllll}2014 & 2019 & 2024 & 2029 & 2034 & 2039\end{array}$ \\
\hline 1 Jumlah & jiwa $\quad 243825520 \quad 26649278292006130347$ \\
\hline 2 Tingka & $\begin{array}{llllll}70 & 70 & 70 & 70 & 70 & 70\end{array}$ \\
\hline 3 Jumlah & jiwa $\quad 17107 \quad 17864186551948020342 \quad 21243$ \\
\hline 4 Kebout & $\begin{array}{lllllll}\text { lthorghr } & 80 & 80 & 80 & 80 & 80 & 80\end{array}$ \\
\hline 5 Jumlah & 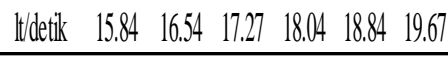 \\
\hline 6 Jumlah kebutuhan air non domesti & $\begin{array}{lllllll}\text { ltddetik } & 5.66 & 5.91 & 6.17 & 6.44 & 6.73 & 7.02 \\
\end{array}$ \\
\hline $7 \mathrm{KEBU}$ & Itddetik $21.50 \quad 22.45 \quad 23.44 \quad 24.48 \quad 25.56 \quad 26.69$ \\
\hline $8 \begin{array}{r}\text { Jumlah } \\
(20 \% x\end{array}$ & $\begin{array}{lllllll}\text { Itdetik } & 4.30 & 4.49 & 4.69 & 4.00 & 5.11 & 5.34\end{array}$ \\
\hline 9 KEBUT & $\begin{array}{lllllll}\text { Itddetik } & 25.80 & 26.94 & 28.13 & 29.37 & 30.68 & 32.03\end{array}$ \\
\hline $10 \begin{array}{l}\text { Kebutuhan harian maksimum } \\
(1,15 \mathrm{x} \mathrm{keb.} \mathrm{rata-} \mathrm{rata})\end{array}$ & Itdetik $\quad 29.67 \quad 30.98 \quad 32.35 \quad 337.78 \quad 35.28$ \\
\hline $\begin{array}{l}\text { Kebutuhan air pada jam puncak } \\
(1,75 x \text { keb. rata- rata) }\end{array}$ & Itdetik $\quad 45.14 \quad 47.14 \quad 49.23 \quad 51.41 \quad 53.6$ \\
\hline
\end{tabular}

\section{Simulasi Pola Operasi Embung}

Pola operasi embung bertujuan untuk membuat keseimbangan antara volume tampungan, debit masukan (inflow) dan keluaran (outflow). Dalam simulasi atau analisa perilaku operasi embung bertujuan untuk mengetahui perubahan kapasitas tampungan embung. Volume tampungan maksimum operasi Embung Sukodono 1,547 juta m3 yang akan dijadikan acuan pola operasi embung untuk kebutuhan air baku dan air irigasi. Simulasi akan terbagi menjadi 3 alternaif pemompaan diantaranya ialah

1. Debit pemompaan sesuai data perencana sebesar $230 \quad$ lt/dtk selama 12 jam sepanjang tahun. Gambar 4 menunjukkan Inflow dan Outflow Alternatif 1. Gambar 5 menunjukkan Keadaan Muka Air Embung Alternatif 1. 


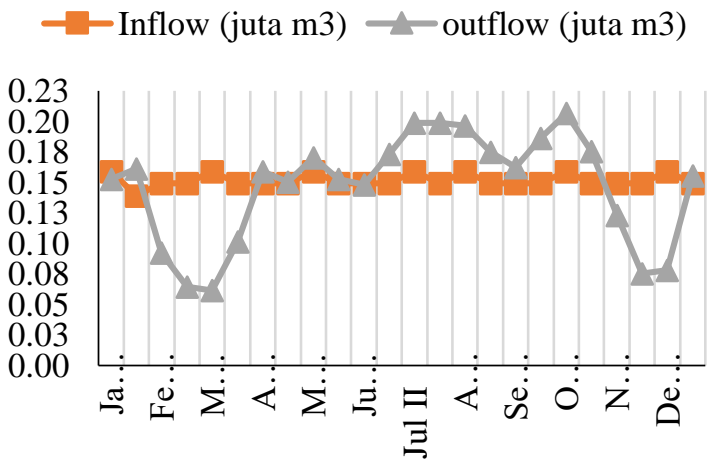

Gambar 4. Grafik Perbandingan Inflow dan Outflow Alternatif 1

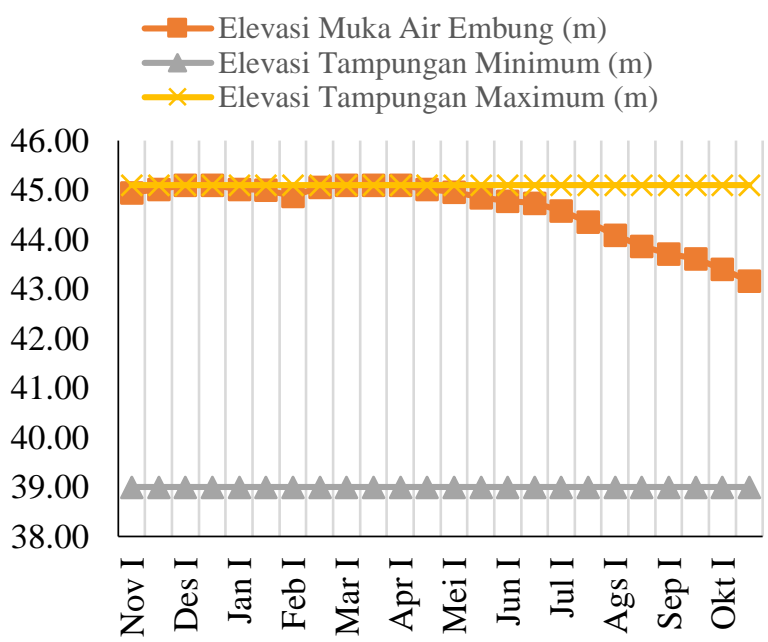

Gambar 5. Grafik Keadaan Muka Air Embung Alternatif 1

2. Debit pemompaan sebesar $230 \mathrm{lt} / \mathrm{dtk}$ pada musim basah dan 200 lt/dtk pada musim kering selama 12 jam. Gambar 6 menunjukkan perbandingan Inflow dan Outflow Alternatif 2. Gambar 7 menunjukkan Keadaan Muka Air Embung Alternatif 2

$\neg$ Inflow (juta m3) - outflow (juta m3)

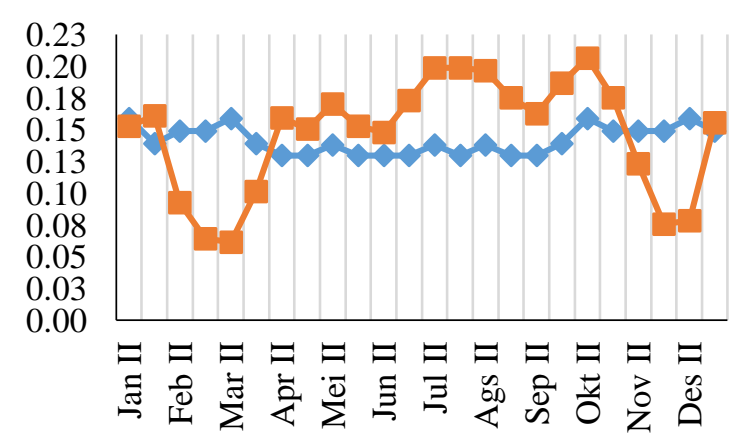

Gambar 6. Grafik Perbandingan Inflow dan Outflow Alternatif 2

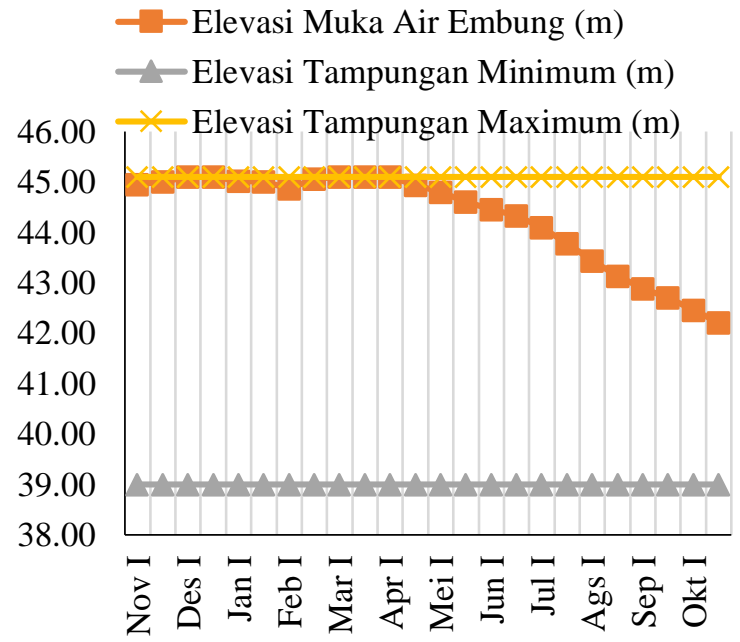

Gambar 7. Grafik Keadaan Muka Air Embung Alternatif 2

3. Debit pemompaan sebesar $230 \mathrm{lt} / \mathrm{dtk}$ pada musim basah selama 12 jam dan 200 lt/dtk pada musim kering selama 8 jam. Gambar 8 menunjukkan perbandingan Inflow dan Outflow Alternatif 3. Gambar 9 menunjukkan keadaan Muka Air Embung Alternatif 3

- Inflow (juta m3) -5 outflow (juta m3)

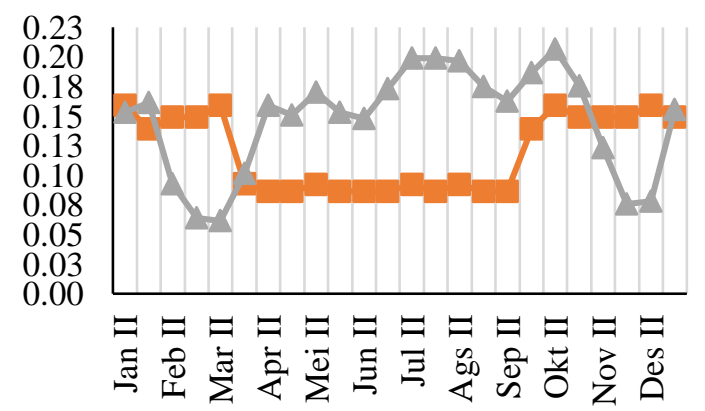

Gambar 8. Grafik Perbandingan Inflow dan Outflow Alternatif 3

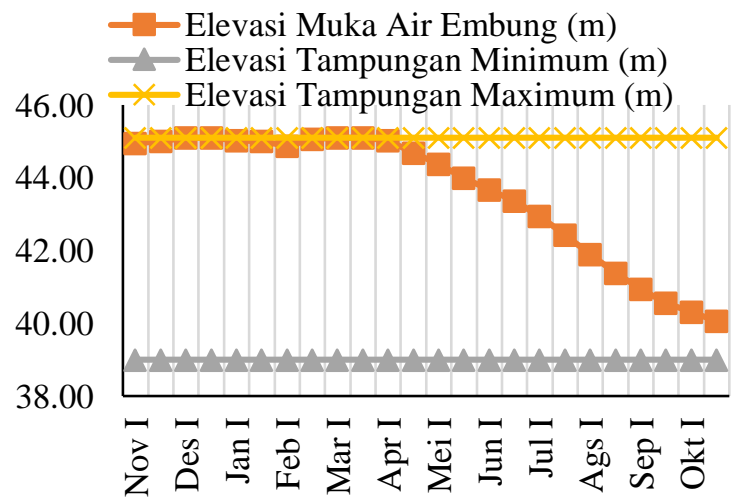

Gambar 9. Grafik Keadaan Muka Air Embung Alternatif 3 


\section{Pembahasan}

Setelah dilakukan perhitungan sesuai alternatif rencana pola operasi embung, berdasarkan grafik muka air embung serta kapasitas debit pemompaan dan lama nya pemompaan dapat ditarik kesimpulan bahwa alternatif 3 merupakan rencana pola operasi Embung Sukodono yang paling efisien dibanding alternatif 1 dan alternatif 2 . Hal ini karena pada alternatif 3, kapasitas debit pemompaan dapat diturunkan dari $230 \mathrm{lt} / \mathrm{dtk}$ menjadi $200 \mathrm{lt} / \mathrm{dtk}$ pada musim kering dan lama pemompaan dapat diturunkan dari 12 jam pemompaan menjadi 8 jam pemompaan pada musim kering namun elevasi muka air embung tetep terjaga di atas elevasi tampungan minimum operasi.

Selanjutnya alternatif 3 rencana pola operasi Embung Sukodono akan dijadikan acuan rencana pola operasi Embung Sukodono selama 25 tahun. Keadaan muka air embung alternative 3 selama 25 tahun tersaji pada Gambar 10.

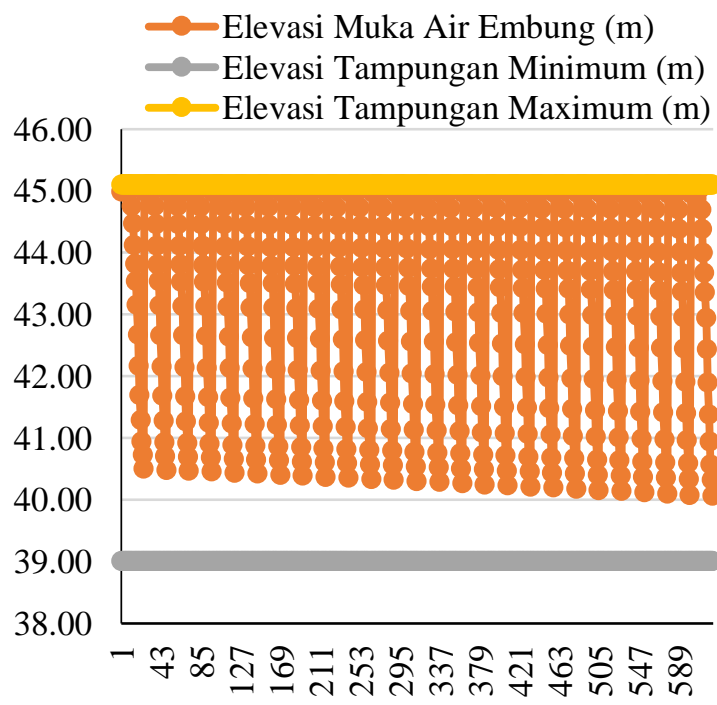

Gambar 10. Grafik Keadaan Muka Air Embung Alternatif 3 Selama 25 Tahun

\section{KESIMPULAN DAN SARAN}

\section{Kesimpulan}

- Kebutuhan air baku untuk Kecamatan Panceng dan Kecamatan Dukun adalah

- kondisi eksisting tahun 2014

- Kebutuhan air normal $=33,94$ liter/detik
- Kebutuhan air pada jam puncak $=59,40$ liter $/$ detik

- Proyeksi tahun 2039

- Kebutuhan air normal $=42,15$ liter $/$ detik

- Kebutuhan air pada jam puncak $=73,36$ liter $/$ detik

- Kebutuhan irigasi untuk kawasan sentra jagung seluas $250 \mathrm{Ha}$ dengan pola tanam rencana ( palawija - palawija - palawija ) adalah

- Kebutuhan irigasi minimum $=0,03 \mathrm{~m}^{3} /$ detik

- Kebutuhan irigasi maksimum $=0,25 \mathrm{~m}^{3} /$ detik

- Rencana pola operasi Embung Sukodono

- Alternatif 1 :Debit pemompaan sesuai data perencana sebesar 230 lt/dtk selama 12 jam sepanjang tahun.

- Alternatif 2 :Debit pemompaan sebesar $230 \mathrm{lt} / \mathrm{dtk}$ pada musim basah dan 200 1t/dtk pada musim kering selama 12 jam.

- Alternatif 3: Debit pemompaan sebesar 230 lt/dtk pada musim basah selama 12 jam dan 200 lt/dtk pada musim kering selama 8 jam.

\section{Saran}

Dalam Pengerjaan tugas akhir penulis mencoba memberikan saran berdasarkan kesimpulan yang ada yang mana ialah jumlah debit dan lama pemompaan dapat diturunkan dan dapat disesuaikan dengan musim yang ada baik musim basah ataupun musim kering sehingga embung dapat beroperasi dengan baik dan lebih efektif penggunannya. 


\section{DAFTAR PUSTAKA}

Badan Meteorologi Geofisika dan Klimatologi. (2017). Data Iklim 2016 2017.

Direktorat Jenderal Pengairan Pekerjaan Umum. (2013). Kriteria Perencanaan Bagian Jaringan Irigasi (KP-01).

Isqak, Dediek. (2011). Analisa Pola Operasi Embung Joho Untuk Pemenuhan Kebutuhan Air Bersih Desa Joho Kecamatan Pace Kabupaten Nganjuk Jawa Timur. Malang : UB.

Kementerian Pekerjaan Umum Dan Perumahan Rakyat. (2015). Rencana Pengelolaan Sumber Daya Air Wilayah Sungai Bengawan Solo.

McMahon, A.T., Mein, G.R. (1978). Reservoir Capacity and Yield. Australia: Elsevier Scientific.

Raghunath, H. M. (2006). Hidrology Principles Analysis Design. New Delhi : Penerbit New Age International Publisher.

Soemarto,C.D. (1986). Hidrologi Teknik. Surabaya : Penerbit Usaha Nasional.

Soewarno. 2000. Hidrologi Operasional. Bandung : Penerbit PT. Citra Aditya Bakti.

Sosrodarsono, S., Takeda, K. (1976). Hidrologi Untuk Pengairan. Jakarta: Pradnya Paramita.

Widyawati, Elok N. (2018). Studi Pemanfaatan Air Waduk Untuk Kebutuhan Air Baku Dan Air Irigasi Pada Waduk Tukul Desa Karanggede Kecamatan Arjosari Kabupaten Pacitan. Malang : Universitas Muhammadiyah Malang. 